\title{
Food imprinting in domestic chicks as a function of social contact and number of companions
}

LAWRENCE H. FRANK and MERLE E. $M E Y E R$, Western Washington State College, Bellingham, Wash. 98225

Three-day-old cockerel chicks were trained to peck a green stimulus for food in preference to a blue stimulus within a social, visual, or isolated condition (Experiment 1), or within a 1, 2, 3, or 4-5 group (Experiment 2). The chicks were tested on four subsequent nonreinforced days to ascertain the generality of "food imprinting." On the initial reinforced day, the chicks discriminated between the two stimuli. The social group pecked more than the visual group and the visual more than the isolated, and the larger the group number, the higher the mean rate. Over the nonreinforced days, all groups showed a rapid decline in the frequency of responses. The data were interpreted as extinction rather than as "food imprinting."

Hess (1964), in extending the general principles of imprinting to that of food imprinting, has argued that in food imprinting the stimulus to which the chick has been exposed during the critical period continues to function as an unconditioned stimulus without a decline in response strength. In the Hess studies, the chicks were imprinted in groups, and the possibility arose that his food imprinting data were in part a function of social facilitation. Meyer \& Frank (1970) have examined this possibility. They trained their experimental chicks to peck a nonpreferred green stimulus for food in preference to a blue stimulus at various age levels within both socialized and isolated conditions. On the initial reinforced day, the experimental chicks responded more to the green stimulus, older chicks responded more than younger birds, and those within the socialized condition responded more than the isolated ones. Over subsequent nonreinforced days, Meyer and Frank observed a rapid decline in the frequency of responses for all groups and interpreted the data as extinction. However, like Hess's birds, the experimental 3-day-old socialized chicks tended to maintain a high percentage of responses to the green stimulus throughout the nonreinforced sessions.

The present research constitutes a further examination of food imprinting with emphasis upon two variables of social facilitation.

\section{EXPERIMENT 1}

Tolman $(1964,1965)$ has reported that, in his investigation of feeding behavior of domestic chicks, feeding was related to unrestricted interaction among chicks. The present experiment investigated the variable of social and visual contact upon food imprinting.

\section{Subjects}

The chicks were 48 White Leghorn cockerels (Kimber) obtained from a local commercial hatchery on the day of hatching. Within the laboratory, the chicks were maintained in a $30^{\circ} \mathrm{C}$ brooder box in groups of 24. Albers Trip-L-Duty Paketts poultry feed was used in maintenance and during the experimental sessions. Food and water was available except for a 4-h food-deprivation period each day prior to the experimental session. Apparatus

The apparatus was a modified Hess pecking-preference box. It was constructed in such a manner that either Masonite or Plexiglas panels could be inserted to convert the $20 \times 20 \mathrm{~cm}$ box into four $10 \times 10 \mathrm{~cm}$ individual compartments. The inside walls of the box were painted a flat gray and were $28 \mathrm{~cm}$ high. The floor was covered with hardware cloth and the top of the box was open. Within each of the individual compartments were two stimuli, a green circle and a blue circle, each $2.5 \mathrm{~cm}$ in diam, and in the center of each stimulus was a $6-\mathrm{mm}$ aperature. The distance between the apertures of the two stimuli was $4.5 \mathrm{~cm}$ and the apertures were $5.8 \mathrm{~cm}$ above the floor. Behind each aperture was a plastic food holder. When the chick pecked the aperture, it activated a microswitch (RW 8435, Microswitch Co.) which, in turn, was recorded on an individual counter.

Procedure and Experimental Design

The chicks were assigned to either a social-group, a visual-group, or an isolated-group condition. The chicks in the social condition were run in a group of four with unrestricted social contact among them. Within the visual condition,
Fig. 1 (below). Percent of responses of chicks reinforced on the initial day for pecking the green key in a social, visual, or isolated group.

Fig. 2 (right). Mean number of responses of chicks reinforced on the initial day for pecking the green key in a social, visual, or isolated group.

SOCIAL GROUP VISUAL GROUP ISOLATED GROUP

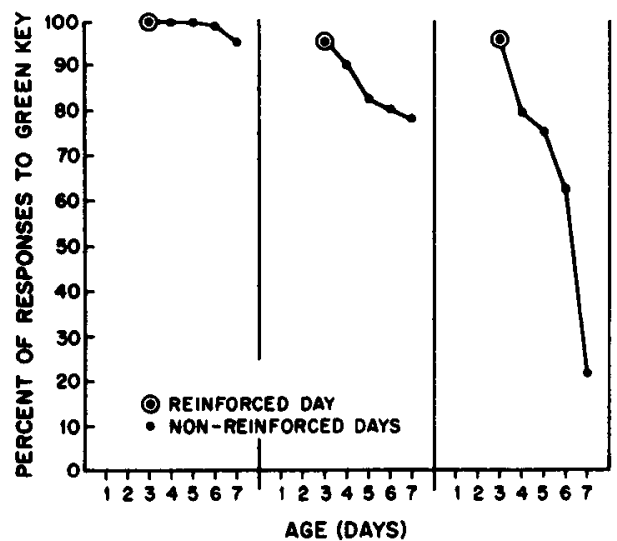

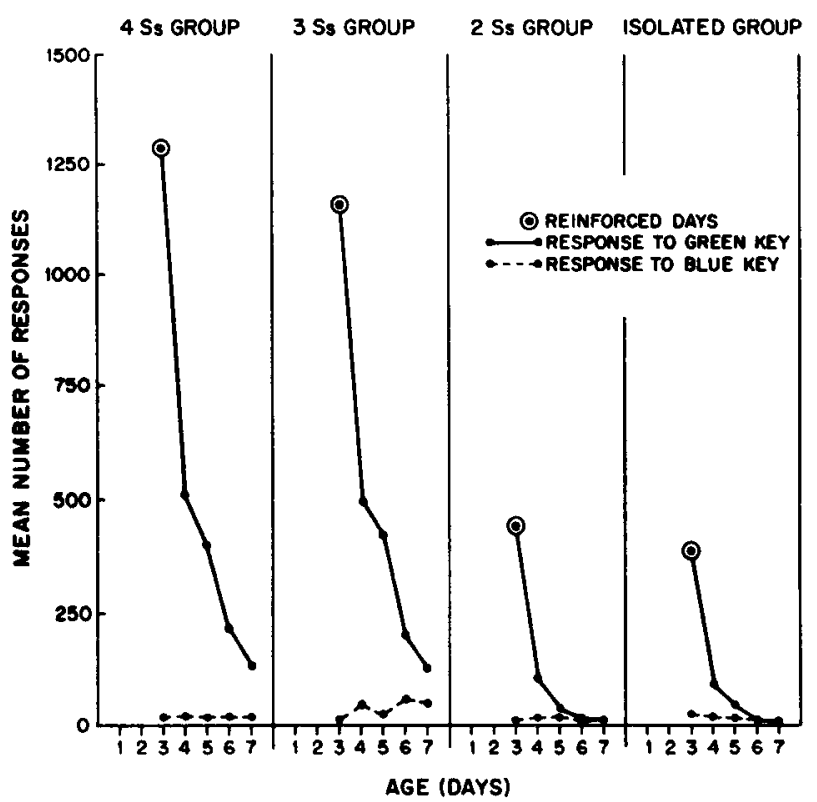


Plexiglas panels were inserted into the box and the chicks were run in a group of four with restricted social contact but with visual contact. In the isolated condition, gray Masonite panels were inserted and the chicks were run in a group of four with both restricted social and visual contact. No attempt was made to restrict the various auditory stimuli within all conditions. Sixteen chicks were in each of the three groups.

At 3 days of age, the birds were deprived of food $4 \mathrm{~h}$ before a 1-h experimental session. During the first-day session, pecking the green circle aperture (the less preferred stimulus; Meyer \& Frank, 1970) was reinforced with food. On the following 4 days, the birds were again deprived of food $4 \mathrm{~h}$ before the 1-h experimental session; however, no food was available during the session. Responses to the blue stimuli (the most preferred stimulus) were not reinforced at any time throughout the sessions. The number of responses to both the green and blue stimuli were separately recorded.

\section{Results and Discussion}

Following Hess's analysis, the percentage of responses to the green stimuli for the various groups is shown in Fig. 1. All groups showed a strong preference for the green stimuli during the initial reinforced day. On the subsequent nonreinforced days, the social group maintained a high percentage of responses which was, for the most part, a replication of both Hess's and Meyer and Frank's findings. This analysis, using percent values, can be interpreted as evidence for food imprinting. On the other hand, the visual group showed a continued decrease in percentage of responses to the previously reinforced green stimulus on subsequent nonreinforced days. Similarly, the isolated group showed a continued marked decline in responses to the green stimulus. From the percentage-of-response analysis, it is apparent that chicks can be imprinted to food, but that food imprinting is a function of unrestricted social and visual contact among chicks. When the chicks are exposed to restricted interaction, the data suggests that extinction occurs rather than imprinting.

The mean frequencies of the pecking responses for the various groups to the green and blue stimuli over days are shown in Fig. 2. The analysis of variance on the responses to the green stimuli yielded a significant difference among the three groups $(p<.05)$ during the initial reinforced day. Multiple comparisons were made using the Newman-Keuls test, and all groups differed significantly $(p<.05)$. The social group responded at a significantly higher rate than the visual group, and the visual group higher than the isolated group. It appears from these data that the rate of response was a function of the social and visual contact among chicks. Nonsignificant differences were obtained from an anlysis of variance of the responses of the various groups to the blue stimuli (p>.05).

The rapid decline in response frequencies over the nonreinforced days is one of the most dominant features in Fig. 2. The decline occurred in response to both the green and the blue stimuli but was most pronounced to the green or prior reinforced stimulus. These data in terms of mean frequencies of the pecking responses may be interpreted as extinction of a discriminative stimulus and are inconsistent with imprinting interpretation.

\section{EXPERIMENT 2}

Meyer \& Frank (1970) have reported differences between isolates and socialized birds in groups of four. Experiment 2 investigated the function of the number of companions upon food imprinting.
Subjects

Sixty-three White Leghorn cockerel chicks were used in this experiment. They were obtained from the same source and maintained in the same fashion as described in the prior experiment.

\section{Apparatus}

The apparatus was the same as that used in Experiment 1 with one exception. Masonite panels were constructed in such a manner that the box could be divided into one, two, three, or four $10 \times 10 \mathrm{~cm}$ areas.

Procedure and Experimental Design

Chicks were assigned to a group of four, three, two, or isolated Ss. Sixteen chicks were in each of the four-, two-, and isolated-group conditions, and 15 birds were in the three-S group. The general procedure was identical to that described in Experiment 1.

Results and Discussion

The percentage of responses to the green stimuli for the various sizes of groups is shown in Fig. 3. As in the prior studies, all groups showed a definite response preference to the green reinforced stimuli. One of the most salient features in Fig. 3 is the decrease of responses to the green stimuli for all groups, except for the four-Ss group during the nonreinforced days. The data for the four-Ss group and the isolated group were essentially a replication of Experiment 1. The percentage of responses to the green stimulus was maintained for the four-Ss group and may be interpreted as food imprinting. On the other hand, the responses of the isolated chicks decreased, as did the responses of the isolated chicks in the prior experiment. The groups with three and two chicks maintained intermediate positions. From Fig. 3 it may be seen that the decrease in response preference to the reinforced green stimuli during the nonreinforced days is a function SOCIAL GROUP VISUAL GROUP ISOLATED GROUP

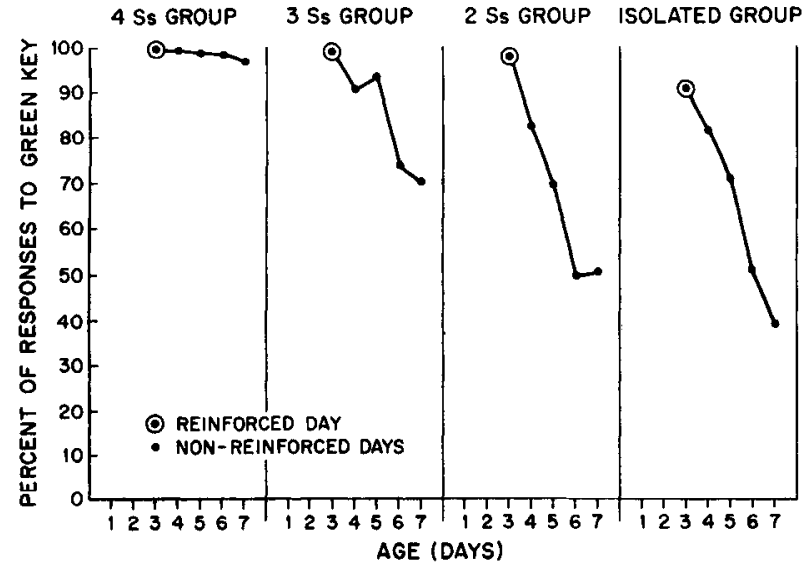

Fig. 3. Percent of responses of chicks reinforced on the initial day for pecking the green key in an isolated 2 , 3 , or 4-5 group.

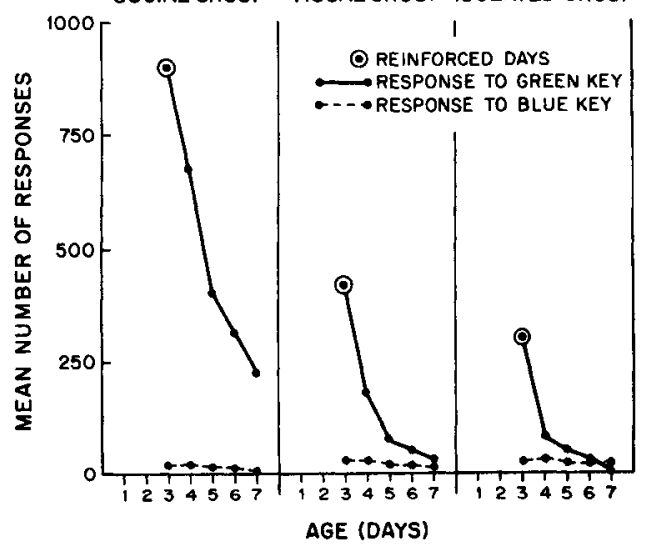

Fig. 4. Mean number of responses of chicks reinforced on the initial day for pecking the green key in an isolated 2,3 , or 4-5 group. 
of the size of the groups or the number of companions.

Figure 4 shows the mean frequencies of responses to the green and blue stimuli by the various number of companions in the groups. A significant difference $(p<.05)$ was found among the four groups. From the multiple comparisons, the groups with four and three Ss did not differ significantly, nor did the two-Ss group and the isolated group $(\mathrm{p}>.05)$. However, all other comparisons were significant $(\mathrm{p}<.05)$.

As in Experiment 1, the rapid and continued decline in responses to the green stimulus on the nonreinforced days dominate Fig. 4. In terms of the mean frequencies, these data may be further interpreted as extinction and are further inconsistent with the interpretation of imprinting.

\section{GENERAL DISCUSSION}

If the data are transformed into percentage of responses, there are some evidences for a food imprinting interpretation. However, food imprinting is a function of both unrestricted social and visual interaction among companions and the number of companions. It is apparent that the presence of other chicks is absolutely essential for food imprinting to occur.

If, on the other hand, the data are analyzed in terms of the mean frequency of responses, there are no evidences to support the food imprinting interpretation. However, the data can be clearly interpreted in terms of association learning processes. From an associative learning interpretation, the various extinction curves are a function of the various experimental conditions. It appears that the various interpretations may be a function of the analysis that was utilized. At present, as parsimony would dictate, there are no dissimilarities between food imprinting and associative learning.

\section{REFERENCES}

HESS, E. H. Imprinting in birds. Science, 1964, 146, 1128-1139.

MEYER, M. E., \& FRANK. L. H. Food imprinting in the domestic chick: A reconsideration. Psychonomic Science, in press.

TOLMAN, C. W. Social facilitation of feeding behavior in the domestic chick. Animal Behaviour, 1964, 12, 245-251.

TOLMAN, D. W., \& WILSON, G. F. Social feeding in domestic chicks. Animal Behaviour, $1965,13,134-142$

\section{The effect of magnesium pemoline on}

\section{discrimination learning and exploratory}

behavior $^{1}$

\begin{abstract}
CLIFFORD KNOX and PAUL GENDREAU, ${ }^{2}$ Trent University, Peterborough, Ont., Canada
\end{abstract}

\begin{abstract}
A drug group was injected interperitoneally with $10 \mathrm{mg} / \mathrm{kg}$ body weight of magnesium pemoline in tragacanth and a control group received the vehicle substance only. The animals were tested on a two-alternative forced choice brightness discrimination task and an open-field test of exploratory behavior. The drug group (1) increased exploratory behavior; (2) produced superior percentage correct discrimination performance; and (3) decreased running speed. The results indicated that the drug, besides having considerable stimulant properties, enhanced learning. Also, a previous study on magnesium pemoline and discrimination learning was reanalyzed and superior discrimination was found for the drug group.
\end{abstract}

Following the report of Glasky \& Simon (1966) on the facilitating effects of magnesium pemoline (MP) on RNA synthesis, considerable attention has focused on the influence of MP learning. Adams, Crawford, \& Lee (1969) have noted that whereas several studies (Beach \& Kimble, 1967; Filby, Szara, \& Salzman, 1967; Frey \& Polidora, 1967; Kulkami, 1967; Plotnikoff, 1966; Thompson \& Knudson, 1968) have reported MP facilitated performance on conditioned avoidance tasks, considerable disagreement has existed as to whether or not the powerful stimulant properties of MP influenced learning or performance. Further, Chase \& Rescorla (1968), Cylert, Mayer, \& Chapman (1967, and Gurowitz, Lubar, Ain, \& Gross (1967) claimed MP failed to enhance conditioned avoidance. More recently, Bridge \& Hatton (1969) have emphasized the need to distinguish between performance and learning effects of MP. Secondly, they argued that the use of positive reinforcement avoided visceral imbalances caused by shock used in previous MP studies. The present study examined stimulant and learning effects of MP on a two-alternative forced choice (2-AFC) brightness discrimination task (Green \& Swets, 1966) using positive reinforcement. The index of discrimination employed, percentage ratio of correct to incorrect responses, offered a measure of discrimination learning relatively free of response bias caused by MP stimulant effects (Bridge \& Hatton, 1969). Open-field exploratory behavior was the dependent variable for measuring MP stimulant properties. Other indices of MP influence on performance, response latency, and trials to criterion were also recorded.

Of the two studies reporting MP effects on a positively reinforced discrimination task, only Bridge and Hatton found MP to facilitate leaming besides performance. Cooper, Potts, Morse, \& Black (1969) found MP to affect performance but did not analyze percentage-correct discrimination. As part of the present study, the Cooper et al (1969) experiment was reanalyzed on the latter index.

\section{SUBJECTS}

Thirty Sprague-Dawley hooded rats served as Ss. The animals were 70-90 days of age and weighed from 212.0 to $262.0 \mathrm{~g}$. The rats were housed in individual cages and were not handled prior to the experiment.

A Y-maze was used to obtain error and time scores for the brightness discrimination task. The maze arms and the startbox were painted gray, while one goalbox was black, the other white. The maze was $4 \frac{1}{2}$ in wide, $5 \frac{1}{4}$ in. deep, and $30 \mathrm{in}$. from the choice point to the end of the start- and goalboxes. Small metal slides separated the start and goalboxes from the maze arms. The arms and boxes were covered by $1 / 8$-in. clear Plexiglas, which was hinged near the choice point.

Open-field exploratory behavior was measured with a Hebb-Williams maze (Lubar, Boitano, Gurowitz, \& Ain, 1967). The floor of the maze was divided into 36 5-in. squares. The floor and the sides of the Hebb-Williams maze was constructed of 3/4-in. plywood and was left unpainted. The maze floor was bounded only by the four outside walls.

\section{PROCEDURE}

The Ss were divided randomly into two groups. Each $\mathrm{S}$ was weighed on a Mettler electric balance. Drug calculations were based on body weight. The drug was suspended in a $0.3 \%$ tragacanth vehicle. Each $S$ received an interperitoneal (IP) injection of $10 \mathrm{mg} / \mathrm{kg}$ magnesium pemoline $30 \mathrm{~min}$ before the start of each test. A $10-\mathrm{mg} / \mathrm{kg}$ dosage level was chosen as it had been found to be effective in previous MP studies (e.g., Cooper et al, 1969). Control Ss received $2 \mathrm{cc}$ of the $0.3 \%$ solution of gum tragacanth as a placebo injection. The open-field test was conducted a day prior to running the 2-AFC task. 